\title{
Seismic stability of braced excavations next to tall buildings
}

Nick O’Riordan PhD, CEng, FICE, PE(Calif.) Director, Ove Arup and Partners, London, UK
Ibrahim Almufti MS, LEED AP, PE, SE(Calif.)

Senior Engineer, Arup North America Ltd, San Francisco, CA, USA

It can take many years to complete the construction of deep, wide and long excavations in urban environments. In seismically active areas, there is a finite probability that a significant earthquake could take place during the construction period. The designer and builder are confronted with the need not only to maintain control of ground and retaining wall movements during the normal construction conditions but also to protect surrounding buildings during a seismic event. It follows that the seismic loads from adjacent structures and their foundations must be considered together with the available load pathways through the propping system. The paper considers the available methods of design and proposes a performance-based design philosophy in which the temporary shoring system and permanent installation are designed for static loading conditions and for the seismic condition only in as much as the performance objectives of adjacent buildings are achieved for various levels of earthquake shaking. An example of the use of performance-based design is presented for the effects of a $130 \mathrm{~m}$ tall building of $30 \mathrm{~m}$ square plan upon the temporary shoring system for a long and wide excavation. The results obtained are compared with code-based calculations and general conclusions are drawn.

\author{
Notation \\ $B \quad$ width of excavation \\ $G \quad$ secant shear modulus of soil at current shear strain $\boldsymbol{g}$ \\ $G_{\max } \quad$ maximum shear modulus, obtained from shear wave \\ test measurements \\ g gravitational acceleration \\ $N \quad$ selected return period used in Figure 4 \\ $n \quad$ number of years excavation is open \\ $S_{\text {a }} \quad$ spectral acceleration \\ $T \quad$ fundamental/first mode period of structure \\ $\delta w_{\max }$ maximum soil displacement caused by excavation \\ $v \quad$ annual rate of occurrence of earthquake \\ $\sigma_{\mathrm{v} 0}^{\prime} \quad$ initial vertical effective stress \\ $\tau_{\max } \quad$ maximum shear stress
}

\section{Introduction}

Limited available vacant space in urban areas compels many vital facilities, such as public transit systems, parking and building facilities, to be constructed underground. The construction of such facilities typically requires deep, wide and long excavations that can take many years to complete. Large excavations in an urban setting where the excavation site is surrounded by many buildings are very challenging. Excavations that are not adequately shored may adversely affect the surrounding buildings (Ciria, 2001; Davis and Henkel, 1982; Finno et al., 2010). The challenge is further complicated when the effect of seismic interaction between excavations and adjacent buildings is taken into account. In seismically active areas there is a finite probability that a significant earthquake could take place while the excavation is open, as well as during the operation of the completed underground structure. Design codes do not provide adequate coverage for either case.

This paper provides approaches for the seismic design of multipropped, deep excavations adjacent to tall buildings in urban areas. It describes the selection of ground motion and the assessment of the system's response under a seismic event. Figure 1 illustrates common soil-structure interaction situations requiring analysis.

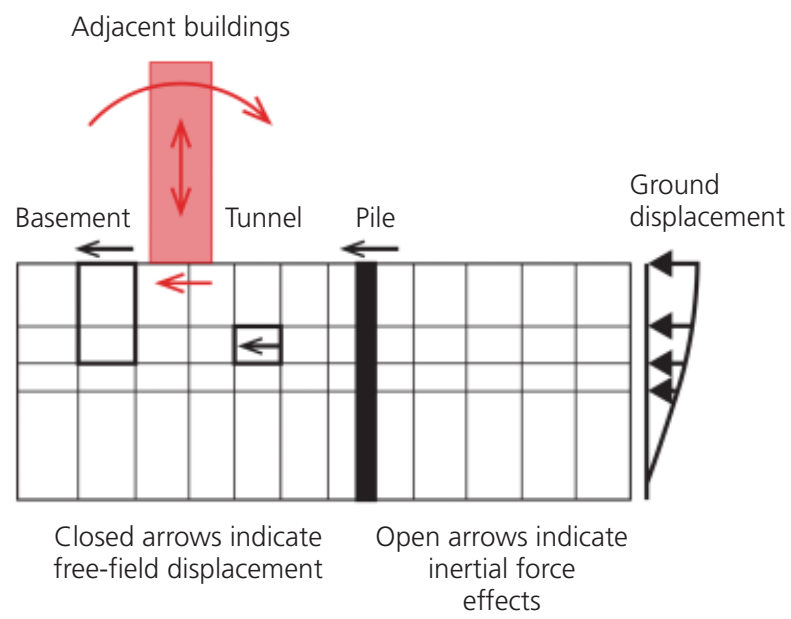

Figure 1. Seismic ground displacements imposed on belowground structures (modified after Free et al., 2001) 


\section{Current methodologies for retaining structures in 'far'-field conditions}

Conventionally, retaining structures are designed using MononobeOkabi (M-O) (Seed and Whitman, 1970) or Wood (1973) equations depending, respectively, on whether the excavated structure is considered to be flexible, mobilising active pressures, or is sufficiently stiff to behave rigidly under seismic loading. Sitar et al. (2012) have challenged these design methods using careful modelling in the centrifuge. They conclude

(a) the M-O method, simplified according to Seed and Whitman (1970), is appropriate for retaining structures of depth, $H$, up to $7 \mathrm{~m}$, with the resultant force applied $H / 3$ from the base

(b) the Wood (1973) solution is not representative of conditions commonly encountered in practice and its continued use is not recommended

(c) caution is needed when applying the $\mathrm{M}-\mathrm{O}$ method to retained depths greater than $7 \mathrm{~m}$, recognising that at some depth the structure will move in a complex manner with the soil.

To deal with retaining structures of greater than $7 \mathrm{~m}$ depth, site response analyses are used with selected ground motions to predict soil deflection profiles in the undeveloped, 'green' or 'far'-field situation. The far-field displacements are then applied as prescribed displacements in a pseudo-static, finite-element, continuum model. The stiffening (or softening effect) of the retaining structure is then examined, to establish a system of design forces acting upon the buried structure (Anderson et al., 2008; Free et al., 2001).

Callisto and Soccodato (2010) describe a methodology to convert pseudo-static displacements obtained by these methods into a design. Unfortunately, again as illustrated in Figure 1, the proximity of large, often very tall buildings is such that in no way can the conditions of the far field pertain, and superposition of displacement fields will underestimate the interaction effect.

Hashash et al. (2010) have extended Anderson et al. (2008) to include various configurations of buried structure, including the increased racking effect from the inclusion of embedded shoring walls. They also compared pseudo-static behaviour with that predicted by dynamic analysis in plane strain situations. However, the effect of adjacent structures is not considered.

\section{Static stability and pseudo-static analysis of excavated structures adjacent to buildings}

Analysis of seismic stability can be complex. In many cases a simple, pseudo-static treatment can be appropriate if there is only limited participation of the adjacent structure in the excavation process under static conditions. Figure 2 shows the displacement field of Bolton et al. (2008), an extension of the various base stability mechanisms considered by Ukritchon et al. (2003). The distribution of prop forces and wall demand is a function of the soil and wall displacement that follows excavation. The displace-

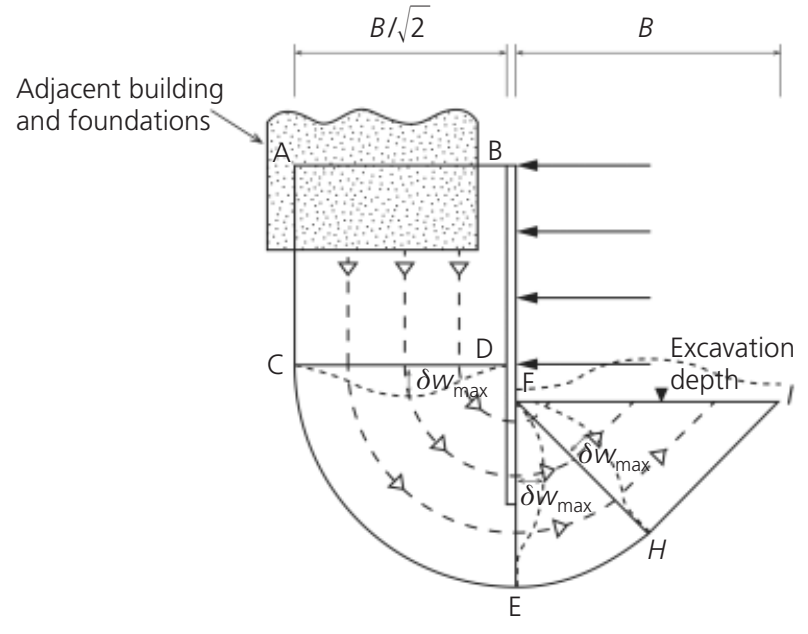

Figure 2. Illustration of the potential participation of adjacent building in the incremental displacement field for a wide excavation (based on Bolton et al., 2008)

ment $(\delta w)$ is partially driven by the foundation of an adjacent structure if it falls anywhere within the zone bounded by the surface ACEDB. The magnitude of the displacement caused by the adjacent structure will be governed by its location within the zone, its stiffness and weight. Ukritchon et al. (2003) examined the stability of a number of multi-propped excavations and found that most operated under a two-dimensional factor of safety of around $1 \cdot 1$ to 1.3 on operational strength of soil in the zone bounded by EFIH. The distance $\mathrm{AB}$ in Figure 2 can be considered to be $B / \sqrt{ } 2$ where $B$ is not less than the half-width of the excavation. The building weight can be represented as a uniformly distributed vertical stress added to the mechanism bounded by ACEDB. It follows that, if that vertical stress exceeds the operational strength of the soil mobilised by that mechanism, then the static stability may be compromised and the seismic loading will further increase the transient and permanent deformation of the wall (represented in part by the dashed line between $\mathrm{D}$ and $\mathrm{E}$ in Figure 2). In turn, this will increase the prop loads and wall demands between props.

Where the seismic loads from a building are derived from codes and then applied to the design of an adjacent excavation (Figure 2), the effects of soil-structure interaction must be considered. In general, buildings designed using codes rely on estimates of accelerations derived for free-field surface motions. This neglects the kinematic effects of embedded basements, which may significantly reduce the demands.

Stewart et al. (1998) examined the performance of individual buildings with embedded basements to strong motions in California. This work is being extended by the activities of ATC-83 (NIST, 2012); however, the interaction of adjacent buildings or underground installations remains at the level of research. Stewart et al. (1998) considered standard code calculation procedures in 
which the foundation is assumed to be rigid, fixed at the base and subject to free-field representation of ground acceleration. They found that

(a) the fundamental period of the structure increases with the explicit inclusion of a foundation system and at higher aspect ratios (height/width), decreasing the flexural demands in the building

(b) there was little apparent difference between structures on piled and shallow foundations.

In addition, higher mode response, which generally governs the shear demands in tall buildings, may be greatly reduced when kinematic effects are accounted for deep embedded basements (Stewart and Tileylioglu, 2007).

This means that the use of code-based seismic forces in a twodimensional pseudo-static analysis will tend to produce an overestimate of the demand on the structural support system for the underground structure where

- structural foundations fall within the zone ACEDB of Figure 2

- the vertical stress that it imposes is lower than the operational strength of the soil.

For situations with an operational soil strength of about $100 \mathrm{kPa}$ below line $\mathrm{CD}$ in Figure 2, adjacent buildings lower than about 15 storeys would fall into this category.

Pseudo-static analysis can be appropriate for buildings with fundamental period, $T<2 \mathrm{~s}$, provided that the inclusion of the building load does not reduce the factor of safety against basal heave to below 1.3. Furthermore, owing to the potential for conservatism in static design procedures, Bray et al. (2010) have suggested that seismic earth pressures on retaining walls can be ignored where the peak ground acceleration (PGA) is less than $0 \cdot 3 \mathrm{~g}$. It is therefore unlikely that seismic interaction with such comparatively modest adjacent buildings will be a governing load case.

For taller and/or heavier structures, the pseudo-static load effect can be examined by choosing a reasonable load pathway for the seismic loads and by assuming that the load is transmitted uniformly through the soil through a $40-45^{\circ}$ wedge. For a raft foundation at ground level, the addition of base shear is straightforward. Ways of including lateral loading effect from adjacent piled buildings under static loading conditions are discussed by Kaul (2010) for metro stations.

\section{Seismic performance criteria}

Adjacent buildings apply base overturning moments and shear loads that will usually be out of phase with each other and with the response of the excavated structure. These effects are often referred to as structure-soil-structure interactions (SSSIs). Recent publications on numerical analysis of SSSIs have been limited to structures with foundations on linear elastic foundation soils (e.g. Yahyai et al., 2008). These tend to overstate the amount of interaction at in-plane separation distances less than the width of the smaller structure. Trombetta et al. (2012) carried out centrifuge testing of rigid dissimilar structures founded on pads on dense sand with a site period of $0.6 \mathrm{~s}$. They modelled a lowrise structure adjacent to a $29.6 \mathrm{~m}$ high structure at prototype scale. These tests showed that, where the PGA exceeded $0 \cdot 3 \boldsymbol{g}$, key parameters such as structural drift, foundation rotation and structural demand are adversely affected.

Considerable effort is required to generalise these overall trends in behaviour for above-ground structures. Further complications arise where the adjacent structure involves the removal of soil and an unloading stress path in the adjacent founding soil. The magnitude of the SSSI effect can dominate the design of the excavated structure.

The design of the excavation support system and the associated permanent underground installation adjacent to structures that have a period, $T$, of more than $2 \mathrm{~s}$ is most economically carried out using SSSI techniques. The process comprises the following steps

(a) selection of ground motions and return period

(b) establishment of design basis and properties of adjacent structures, including foundations

(c) computer simulation of excavation process and earthquake performance

(d) comparison of predicted earthquake performance of adjacent structure with design basis

(e) completion of design of temporary support and permanent installation.

Figure 3 shows the code-intended seismic performance objectives for new buildings in the USA. These are designed under the implicit objective of 'life safety' performance in a design earthquake. Although it is not explicitly related to a specific intensity level, the

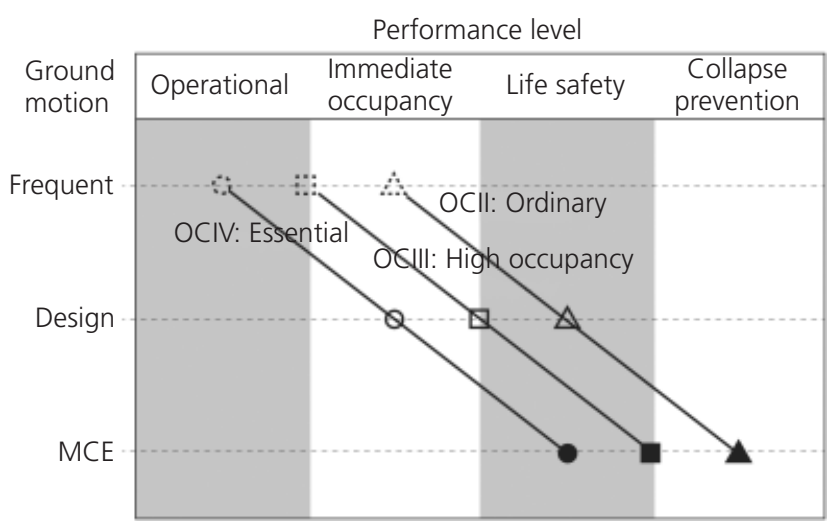

Figure 3. Matrix for code-intended performance objectives (FEMA, 2009) 
design earthquake is approximately equivalent to a 475-year return period earthquake ( $10 \%$ probability of exceedance in 50 years) in California. For comparison, Eurocode 8 (BSI, 2004) adopts a return period of 475 years explicitly and similarly intends for 'life safety' performance. Building performance under 'frequent' earthquakes is rarely considered, although the implicit performance expectation is that new buildings would suffer minimal damage (ASCE 7-10 (ASCE, 2010)) and Eurocode 8 has a 'damage limitation requirement' associated with a return period of 95 years.

For building structures, a performance-based design is used as a means to demonstrate that the performance objectives intended by prescriptive code-based design are explicitly met. The performance objectives are defined by the amount of tolerable damage a building sustains for a particular severity of shaking. To demonstrate the performance objectives are met, a non-linear response history analysis (NLRHA) is typically required.

An analogous methodology may be employed for open excavations in urban areas and enables a focused dialogue to take place between the owner of the underground structure and the adjacent building owner. The general performance-based philosophy is to demonstrate that the seismic performance of surrounding buildings only is not compromised by the excavation and is no worse relative to the performance of the building in the existing condition (i.e. no excavation or shoring system), under a prespecified severity of ground motion (e.g. 'frequent' level). The props and shoring system need not achieve any independent performance objectives separate from the adjacent building's performance objectives (i.e. in an urban area, this implies that stability of the excavated system must not be compromised). This design intent may be attained by the following measures.

(a) Design the props and shoring system for the gravity forces associated with the open excavation in the static condition, ensuring that deflections are kept to acceptable limits.

(b) Check that the adjacent building sustains no more damage under the 'temporary' level earthquake event (see below) in the temporary condition compared to the existing condition (no excavation). Since it is likely that the structural details (and thus non-linear properties of the structural components) in the adjacent building are not available (especially for older existing buildings), it may be necessary to gauge the performance of the building by ensuring the seismic-induced lateral and vertical settlements are within some acceptable limit to be agreed upon by the owner/engineer.

(c) Check that the seismic-induced demands on the props and shoring system in the 'temporary' condition are less than their capacities.

(d) The process should be repeated for each ground motion under consideration, but no less than three motions should be used.

\subsection{Ground motions}

Eurocode 8 (BS EN 1998 (BSI, 2004)) recommends 30\% of the design actions associated with a return period of 475 years are

used for the temporary condition and ASCE 37-02 (ASCE, 2002) implies $20 \%$. To put these recommendations into the context of probability of exposure, Figure 4 examines the situation for the urban centre of San Francisco, whereby acceleration spectra are derived for return periods of 50 and 100 years, normalised with the spectrum for a return period of 475 years. It can be seen that the Eurocode 8 and ASCE 37-02 recommendations, shown bracketed in Figure 4, are reasonable for situations where the fundamental period of the system is greater than $2 \mathrm{~s}$, but not for systems with shorter fundamental periods. These include deep excavations and situations in which adjacent building performance is dominated by higher modes of vibration. For these, it may be more appropriate to define a uniform hazard spectrum for the desired intensity level, as follows.

The frequent-level earthquake ground motion is not defined in the building codes, but several performance-based design guidelines (CTBUH, 2014; PEER TBI, 2014) recommend a return period between 43 and 72 years. Table 1 gives the probability that the

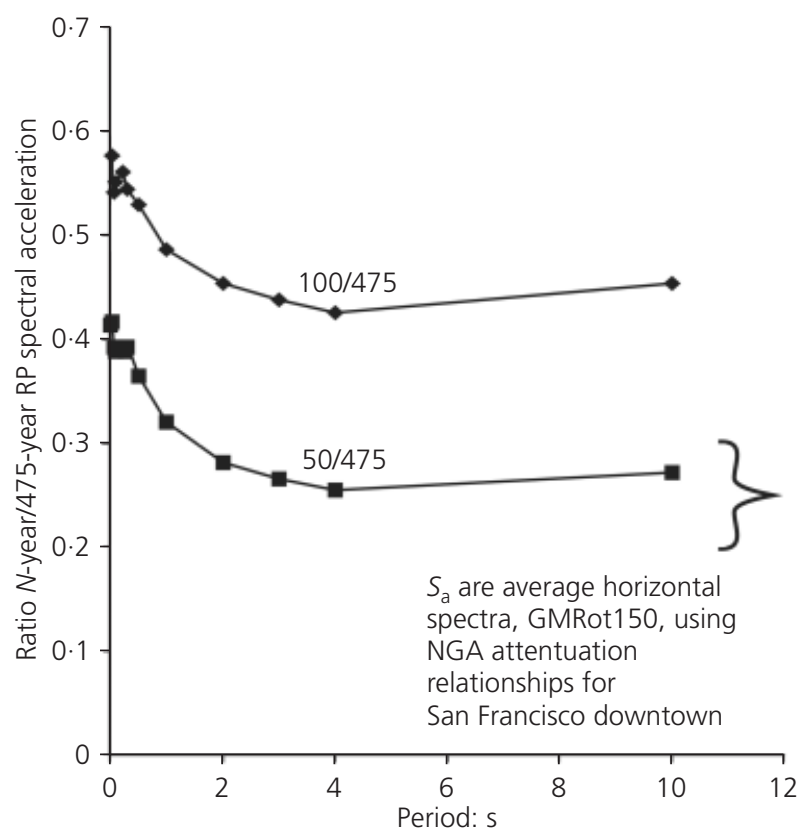

Figure 4. Variation of spectral acceleration ratio with period

Number of years excavation is open

$r$


frequent-level, 50-year earthquake ground motion will be exceeded during the period that the excavation remains open. Table 1 shows that the hazard level for the excavation depends on the length of time the excavation remains open, as well as on the earthquake intensity level. The hazard level is not defined solely by adopting a pre-determined earthquake intensity. For comparison, the 475-year return period earthquake has a $10 \%$ chance of being exceeded in the typically stated lifetime of a building (50 years). Table 1 shows that the utilisation of a 50-year return period earthquake to analyse an excavation that is only open for a few years may be conservative compared to traditional risk tolerance. The values in Table 1 were determined using the following equation

$$
\mathrm{PE}=1-\mathrm{e}^{(-v n)}
$$

where PE is probability of exceedance, $v$ is annual rate of occurrence and $n$ is the number of years the excavation is open. The return period is calculated by $1 / v$.

A hazard level that aligns more closely with the traditional risk tolerance may be obtained as follows.

(a) Use a 'temporary' level earthquake ground motion to assess the seismic response of the adjacent building during the temporary excavation.

(b) Define this 'temporary' level ground motion as having a $10 \%$ probability of exceedance while the excavation is open.

(c) Adopt a lower damping (e.g. $2 \%$ rather than the traditional $5 \%$ ) when generating the response spectrum of the adjacent building. The building is not expected to yield during a lowintensity earthquake and so significant hysteretic damping is unlikely to occur.

(d) An SSSI analysis may then be carried out as described below, to determine the structural demands on the walls and props. These should then be compared to the yield capacities of the individual members and their connections.

\section{Free-field site response}

One-dimensional wave propagation analyses are a standard tool to understand the effects of soil stiffness and thickness on the seismic energy at a location of interest. The analyses can be performed using equivalent linear (Idriss and Sun, 1992) or nonlinear (Kwok et al., 2006) approaches using conventional wave propagation softwares, such as Shake 2000, Deepsoil, Siren and LS-Dyna. Understanding the assumptions and simplifications used in each approach is important when reviewing the results.

These analyses assume that there is no excavation, no shoring system and there are no adjacent structures. The results of the analyses are the free-field seismic response, which can be used as input in the soil-structure interaction analysis. The results of the analyses can be checked by comparing the surface response spectra with spectra established through conventional code-based procedures.

\subsection{Effects of the excavation on soil response}

The response for the soil column directly below the excavation in the long-term future loading condition may not be the same as predicted by the free-field motions at the state of stress in the ground pre-excavation. The excavation has the effect of reducing the effective stresses in the soils to a level below which they cause the stiffness and strength to degrade.

A one-dimensional site response analysis may also be performed using a reduced height of the soil column based on the completed excavation depth to assess the potential of liquefiable soils within the excavation and at depth. The soil properties should be adjusted to account for the reduction in stress and changes to other engineering properties. The shear modulus reduction curve should be adjusted so that the implied shear strength or apparent friction angle is consistent with the new engineering properties and stress state for each layer. The change in the small strain shear modulus can be estimated using many of the available correlations from Seed and Idriss (1970) to Darandeli (2001). An example of the variation in shear modulus with increasing shear strain for a clay of medium plasticity and moderate over-consolidation ratio is given in Figure 5, in which the curve for static analysis (simulating the excavation sequence) is compared to that used for subsequent dynamic analysis at any stage of excavation.

Where the results of one-dimensional analysis show that a layer is liquefiable, its shear strength should be neglected when excavation stability is considered. A one-dimensional site response analysis excludes the stiffness of the shoring and bracing system and should always be complemented by a more complete, three-dimensional soil-structure interaction analysis as follows.

\section{Structure-soil-structure interaction analysis}

Consider, as an extreme example, the tall, heavy building, approximately $35 \mathrm{~m} \times 60 \mathrm{~m}$ in plan, located $10 \mathrm{~m}$ outside an $18.3 \mathrm{~m}$ deep excavation illustrated in Figure 6. In this situation,

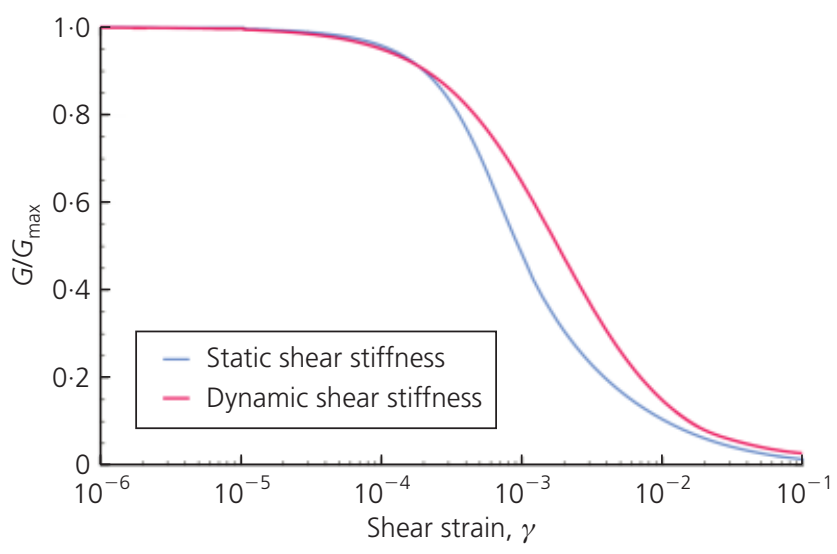

Figure 5. Examples of non-linear secant shear modulus degradation in static and dynamic loading for stiff clay 


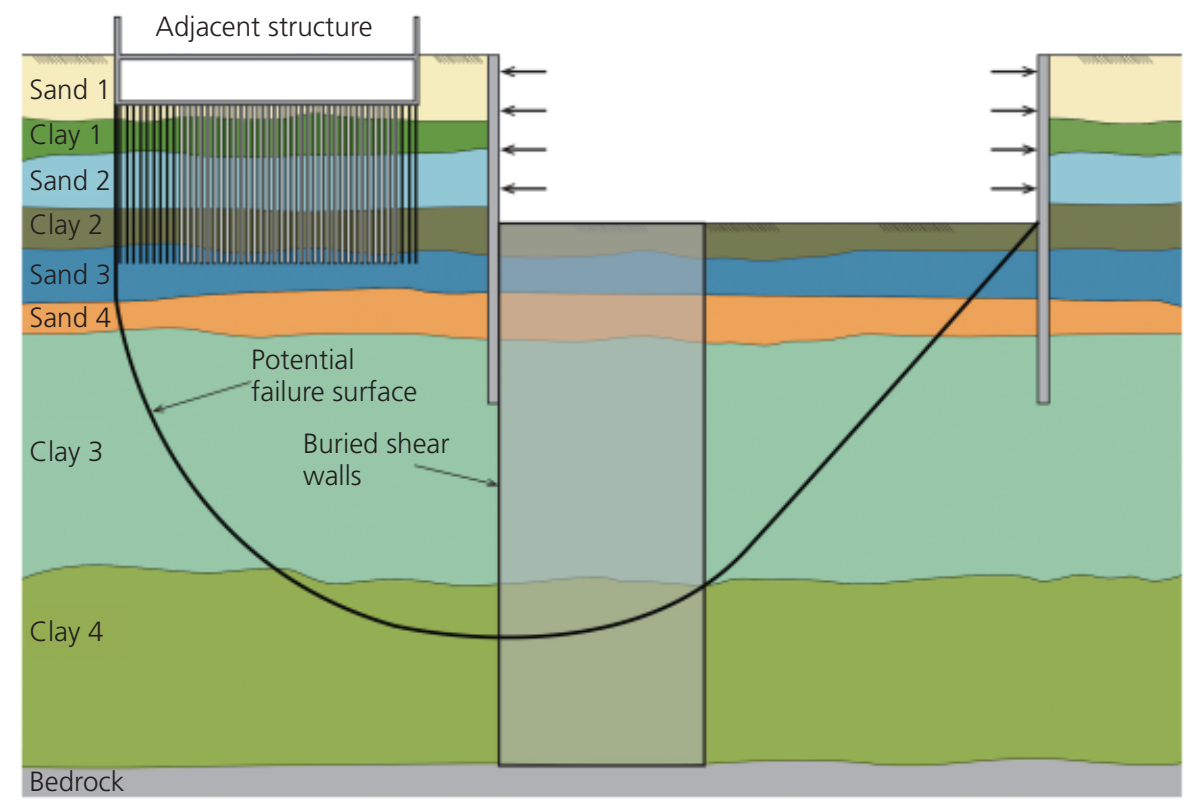

Figure 6. Tall building of equivalent vertical static load of $500 \mathrm{kPa}$ adjacent to $20 \mathrm{~m}$ deep excavation, showing extent of buried shear walls to prevent basal heave

the building load applies a vertical static load of $500 \mathrm{kPa}$. This is approximately four times the operational shear strength of the soils at excavation level, which would be intersected by the potential failure surface shown in Figure 6. In the static condition, the stability of the excavation is slightly less than 1 , and additional deep support is needed. The first mode period of the building is approximately $4.5 \mathrm{~s}$ and the far-field site period is approximately $1.5 \mathrm{~s}$.

\subsection{Buried shear walls}

The soil strength under the excavation, in which zone the potential failure surfaces EFIH in Figure 2 would otherwise form, is enhanced using shear walls, approximately $2 \mathrm{~m}$ wide at $4.5 \mathrm{~m}$ centres with average concrete strength properties of $28 \mathrm{MPa}$ embedded inside the retaining wall to a depth of $60 \mathrm{~m}$ below the excavation, into the underlying bedrock to prevent failure in the static condition. A three-dimensional dynamic analysis using LSDyna (Figure 7) is carried out with unidirectional ground motion perpendicular to the excavation to examine the permanent displacements that are induced by the earthquake and consequently any additional demands on the props and shoring system. For this study, the ground motions associated with a 100 -year return period were used because they had already been developed for the site for separate purposes. Since the excavation is expected to be open for approximately 5 years, this corresponds to a ground motion with $5 \%$ probability of exceedance.

The assessment of excavation behaviour under seismic loading is best completed using NLRHA. The software, as a minimum, explicitly includes

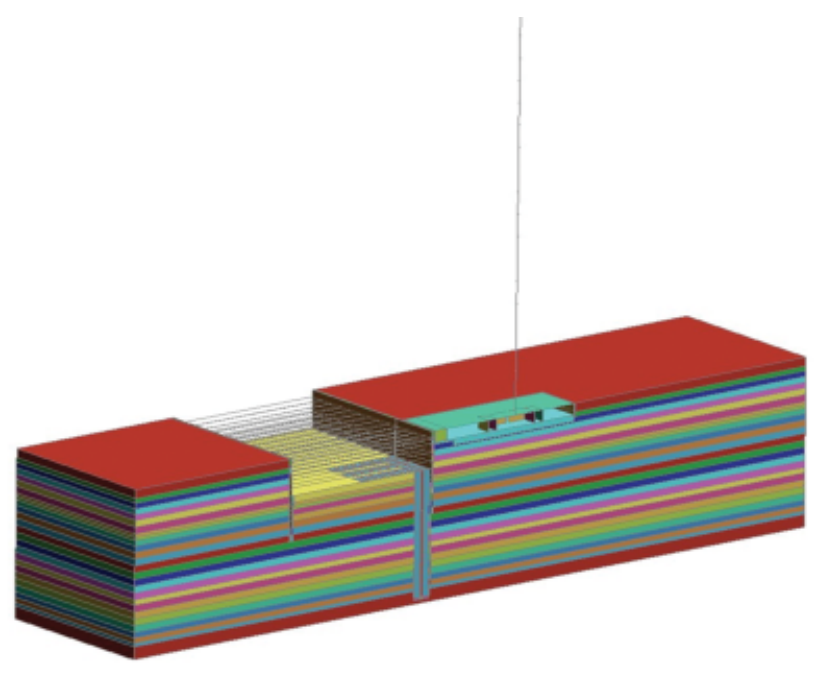

Figure 7. Computer simulation model (LS-Dyna)

pressure-sensitive non-linear shear stress/strain soil properties

- degrading $G / G_{\max }$ curves where $G_{\max }$ is established from shear wave velocity tests

- pore pressures and excess pore pressures associated with the shear strain rates pertaining during excavation and seismic excitation stages

- foundation of surrounding building, including appropriate cracked concrete properties and piles

- representation of the adjacent building, including equivalent mass and stiffness to capture the dynamic behaviour

prop and shoring wall system 
interface layers between structural elements and virgin soils that represent disturbed soil

- soil domain sufficiently large that boundary effects are negligible under seismic loading.

The model for the adjacent building in this analysis may often be based on elastic properties because non-linearity in the structural components is usually minor under 'frequent' level shaking. Damping is assumed to be $2 \%$ of critical which is consistent with new research on tall buildings.

Details of the NLRHA are given in the appendix to this paper. The results show that the overall performance of the building was better in the temporary condition with the open excavation than it was in the existing condition with no excavation. The improvement results from the addition of the buried shear walls to the shoring wall system (see Figure 6). During the earthquake, plastic strains develop in the highly stressed soils beneath the building (Figure 6) and result in permanent settlements. Figure 8 shows the settlements from one of the ground motion scenarios. The vertical, seismically induced settlement with the temporary excavation and shear walls present is slightly less than it would have been if there were no excavation. The other two ground motion scenarios exhibited similar response.

Figure 9 shows the elastic base shear forces at the underside of the adjacent tall building mat arising from earthquake loading. Base shear is similar in both the temporary situation with the

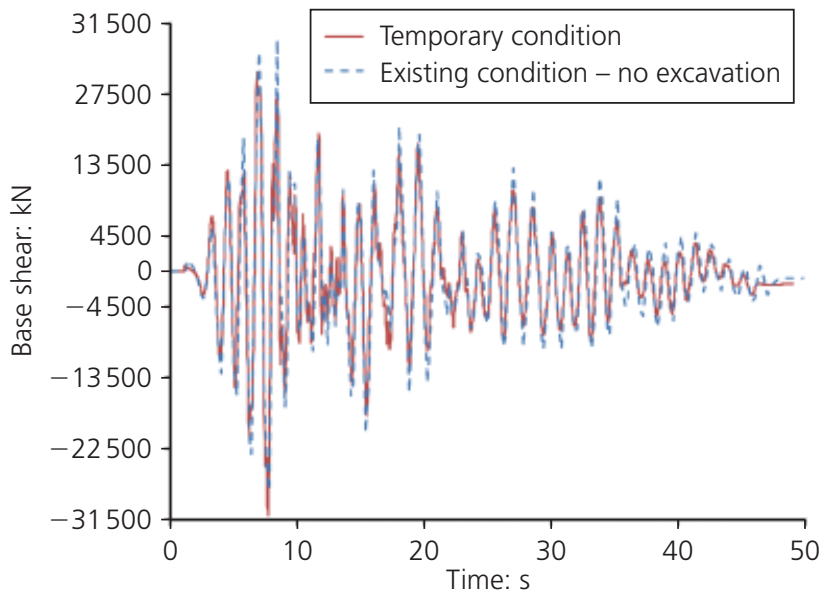

Figure 9. Shear at base of tower (Kobe earthquake input): elastic base shear force at the underside of the mat of the adjacent building

buried shear walls and in the original condition without an excavation. The maximum seismically induced base shear force in the direction of the excavation is about $27500 \mathrm{kN}$, or an average of $785 \mathrm{kN} / \mathrm{m}$ run of the $35 \mathrm{~m}$ wide piled mat.

Next, the seismic demands in the props are investigated to ensure that they are within capacity. Figure 8 shows the prop locations and Table 2 provides a summary of predicted loads at completion

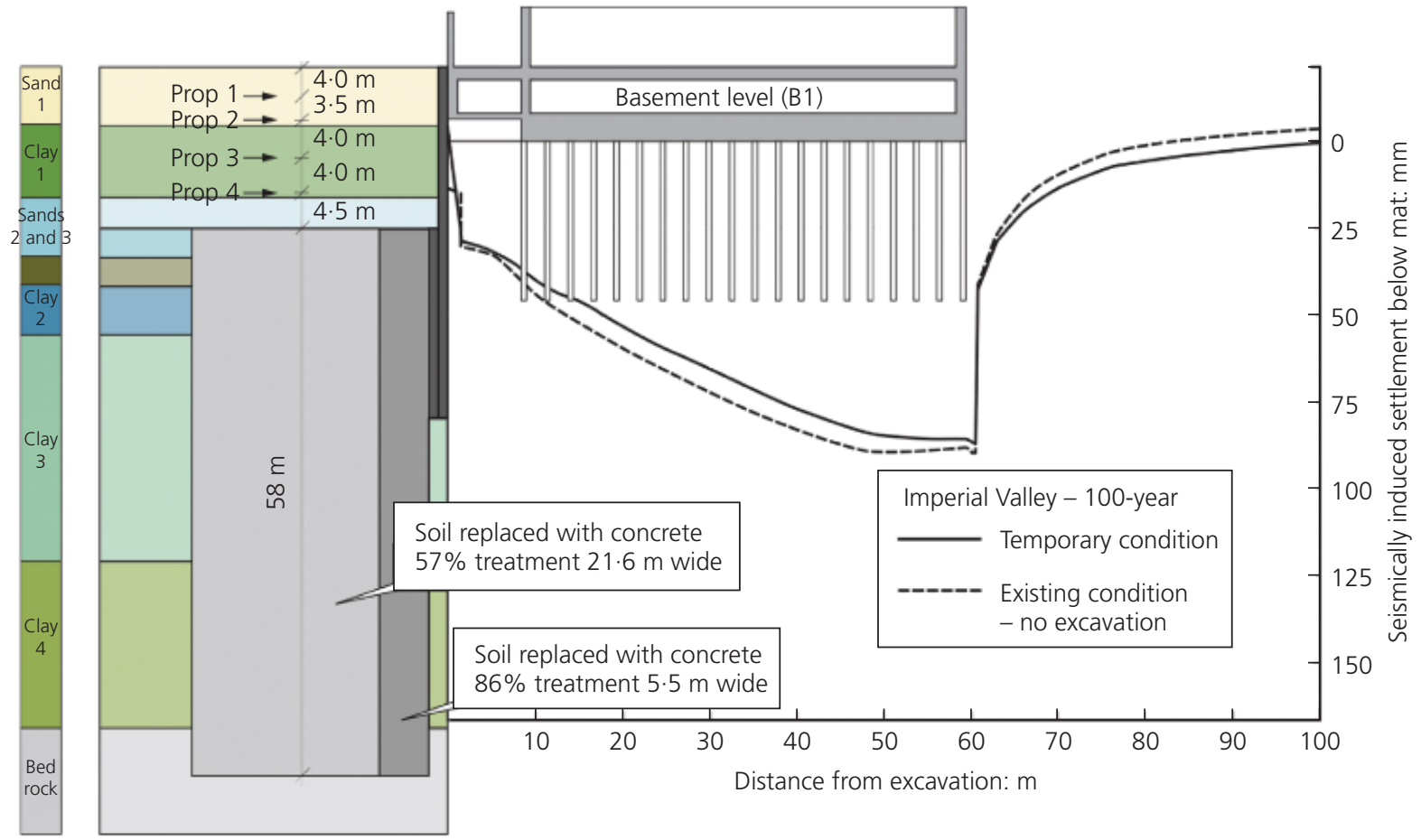

Figure 8. Seismic-induced settlements in temporary and existing conditions 


\begin{tabular}{|c|c|c|c|c|c|c|}
\hline \multirow[t]{2}{*}{ Prop } & \multirow[t]{2}{*}{ Depth: m } & \multicolumn{2}{|c|}{$\begin{array}{l}\text { Completion of excavation (LS-Dyna): } \\
\text { kN/m run }\end{array}$} & \multicolumn{2}{|c|}{$\begin{array}{l}\text { Seismic load increment (LS-Dyna): } \\
\text { kN/m run }\end{array}$} & \multirow{2}{*}{$\begin{array}{c}\text { Seismic load increment } \\
\text { (Wood, 1973): }{ }^{a} \mathrm{kN} / \mathrm{m} \text { run } \\
\begin{array}{c}\text { Remote from } \\
\text { building }\end{array}\end{array}$} \\
\hline & & $\begin{array}{l}\text { Remote from } \\
\text { building }\end{array}$ & $\begin{array}{l}\text { Adjacent to } \\
\text { building }\end{array}$ & $\begin{array}{l}\text { Remote from } \\
\text { building }\end{array}$ & $\begin{array}{l}\text { Adjacent to } \\
\text { building }\end{array}$ & \\
\hline 1 & $4 \cdot 0$ & 160 & 90 & 80 & -10 & 550 \\
\hline 2 & $7 \cdot 5$ & 410 & 390 & 310 & -40 & 410 \\
\hline 3 & $11 \cdot 5$ & 870 & 560 & 220 & -160 & 270 \\
\hline 4 & $15 \cdot 5$ & 660 & 750 & 30 & 560 & 330 \\
\hline
\end{tabular}

a Using the pressure distribution suggested by Matthewson et al. (1980).

Table 2. Summary of predicted prop loads at completion of excavation and after seismic shaking

of excavation and the increment added to those loads after seismic shaking. Values are expressed in $\mathrm{kN} / \mathrm{m}$ run of wall and are given for two locations: adjacent to the building and remote from it, where the buried shear walls are absent. The total force in the remote props is the greater. This is due to the local reduction of lateral stress from the building basement excavation and the mobilisation of lateral resistance through the piled mat of the building and the buried shear wall system.

Figure 10 shows how the prop forces change during an earthquake. The lowest level of props, which are approximately $2.4 \mathrm{~m}$ on centre, are resisting a significant proportion of the seismic load while the loads in the higher levels of props reduce during and after seismic shaking. This behaviour, together with the force distributions remote from the building, are insightful results from NLRHA and are not as expected from code-based formulations. These results can be attributed to three-dimensional effects and, after seismic shaking, to the rotational flexibility of the adjacent building at its base, which tends to unload the top props and

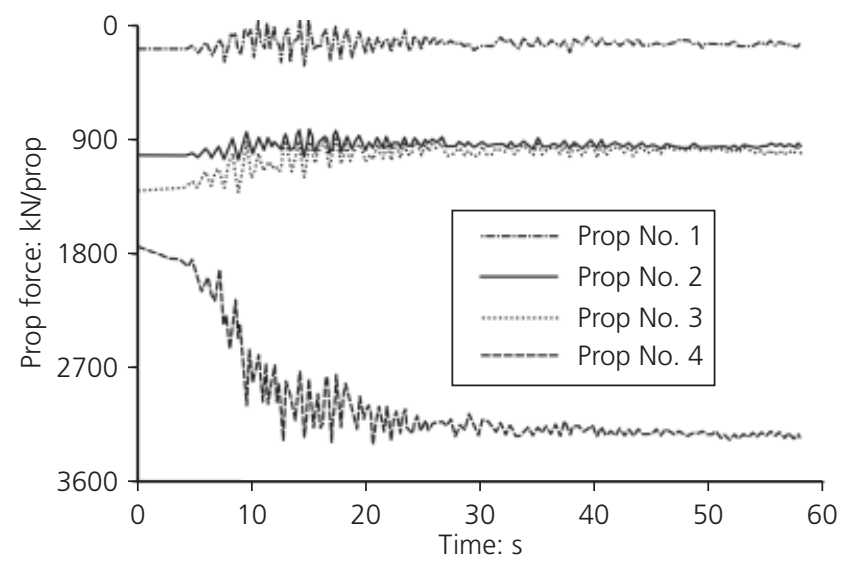

Figure 10. Development of seismic-induced forces in props at $2.4 \mathrm{~m}$ centres (note: static excavation-induced prop forces are shown at time $=0$ ) compress the bottom prop. The rotational flexibility of this building may be greater than most, because the piles are not deeper than the zone CDE illustrated in Figure 2.

This combination of static and dynamic analyses has enabled the examination of the permanent displacements and associated seismic force distributions from a tall, heavy building onto an adjacent multi-propped excavation. The following conclusions are drawn.

(a) The seismic forces taken by the lowest level of props amount to about $75 \%$ of the NLRHA base shear force under the adjacent building mat.

(b) The seismic force attracted to the buried shear wall system below the excavation - that is, the difference between the NLRHA calculated base shear force and the force taken by the props - is approximately $25 \%$ of the base shear force.

(c) The horizontal line of reaction to the base shear is close to the base of the piles of the adjacent building, and this does not conform to the force distribution predicted using conventional pseudo-static formulations such as MononobeOkabe (Seed and Whitman, 1970) or Wood (1973).

(d) The seismic effects on the stability of a multi-propped excavation from adjacent, tall, heavy buildings can be controlled by the construction of buried shear walls within the shoring wall system, and this has the potential to improve the performance of the adjacent buildings under seismic loading.

\section{Conclusion}

Most underground structures built in urban environments will require a temporary shored excavation due to spatial restrictions. The shoring system is designed to provide global stability and to meet performance criteria for static conditions. Meeting the performance criteria can be critical to the success of an excavation, especially when existing structures are present within the zone of deformations outside the excavation.

It is suggested that pseudo-static analysis can be appropriate for buildings with $T<2 \mathrm{~s}$, provided that the inclusion of the building 
Seismic stability of braced excavations

next to tall buildings

O'Riordan and Almufti

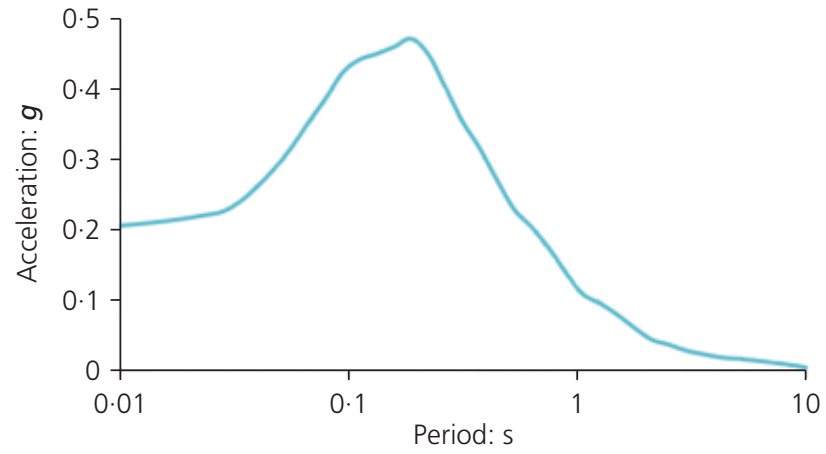

Figure 11. 100-year site-adjusted top of rock mean equal hazard response spectrum

load does not reduce the factor of safety against basal heave to below 1·3. For taller, heavier structures, detailed, dynamic, threedimensional analysis is required.

Numerical analysis tools now allow SSSI analyses that incorporate dynamic, seismic shaking. These tools can help in understanding the complex interaction of the soil, shoring system for the excavation, the completed underground structure and adjacent buildings. The shoring system for a new excavation adjacent to tall, heavy buildings with $T>2 \mathrm{~s}$ and insufficiently deep foundations in areas with $\mathrm{PGA}>0 \cdot 3 \boldsymbol{g}$ will require an augmented shoring system to take account of seismic interaction effects. After the underground structure has been constructed, the effects of new, tall buildings to be sited adjacent to that structure can be evaluated. Tall, heavy buildings with $T>2 \mathrm{~s}$ in areas with PGA $>0 \cdot 3 g$ may well require foundations that are significantly deeper and stiffer than would be required to satisfy only static loading constraints.

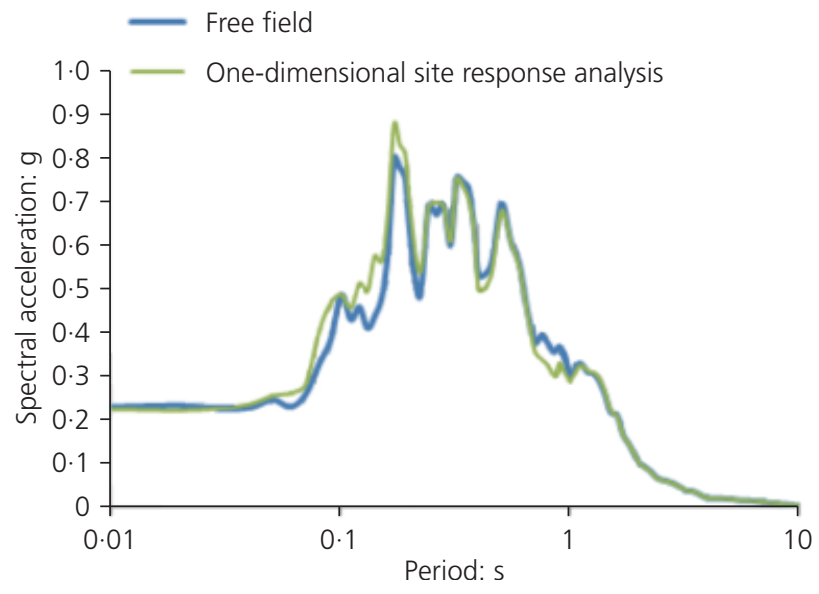

Figure 12. Surface spectra: comparison between free-field response in LS-Dyna and representative one-dimensional site response analysis

\section{Acknowledgements}

The authors are grateful to their colleagues Michael Willford, Brian Simpson, Payman Khalili-Tehrani, Yuli Huang, Kirk Ellison and Stephen McLandrich in supporting this research. The authors also thank the Transbay Joint Powers Authority for the opportunity to publish some of the findings arising from the design of the Transbay Transit Center, San Francisco in this paper.

\section{Appendix: Details of non-linear response history analysis used in the example}

(a) Bedrock input motion (see Figure 11).

(b) Free-field response in LS-Dyna compared to representative one-dimensional site response analysis (Deepsoil) (see Figure 12).

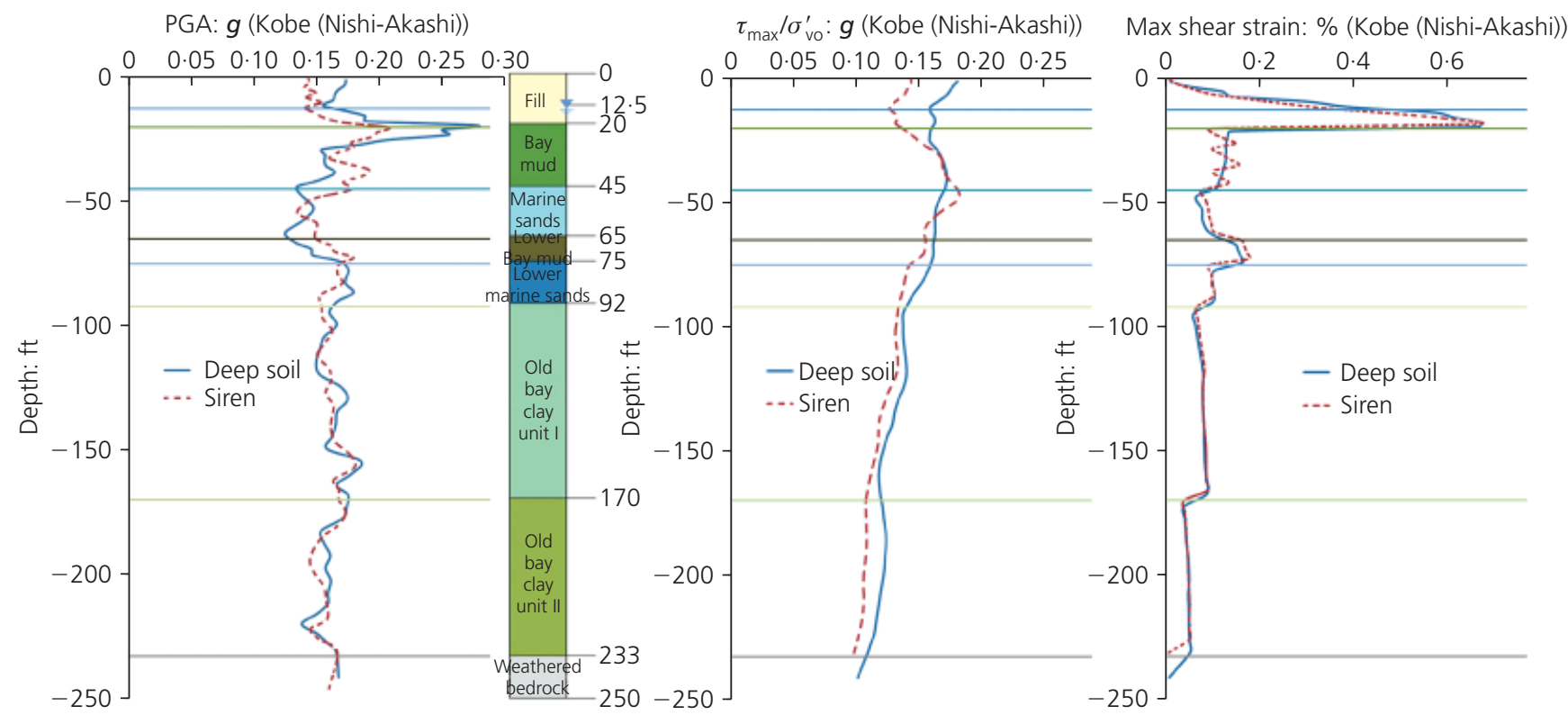

Figure 13. Site response analysis 


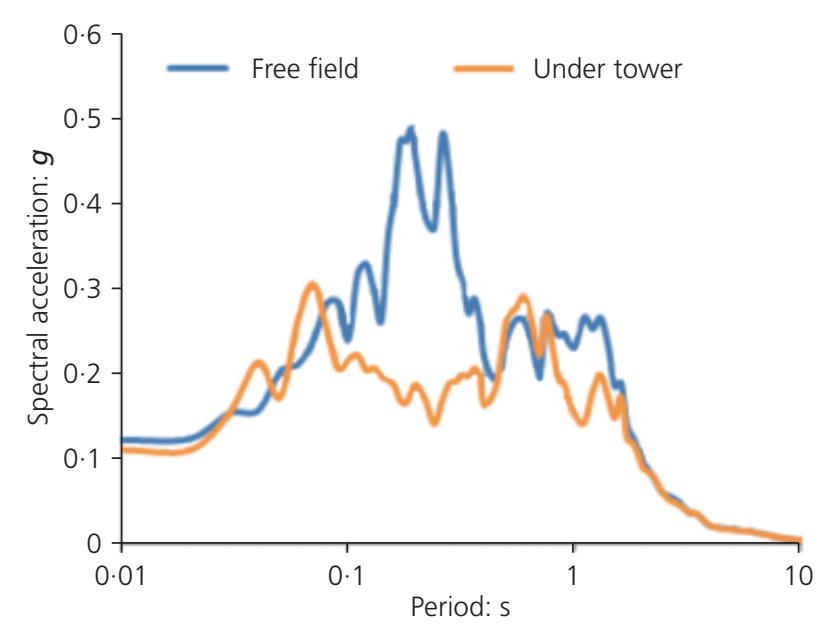

Figure 14. Response spectrum at bottom of mat elevation

(c) Site response analysis (one-dimensional analyses shown: results are similar in LS-Dyna) (see Figure 13).

(d) Response spectrum generated from LS-Dyna analysis at the bottom of the mat (underside of basement B1 on Figure 8) (see Figure 14).

Note that the response under the building is lower than in the free field owing to the local influence of the mass of the building, the stiffness of the piled foundation and the buried shear walls within the adjacent excavation.

\section{REFERENCES}

Anderson DG, Martin GR, Lam I and Wang JN (2008) Seismic Analysis and Design of Retaining Walls, Buried Structures, Slopes and Embankments. National Cooperation Highway Research Programme (NCHRP), Transportation Research Board, Washington, DC, USA, Report 611.

ASCE (American Society of Civil Engineers) (2002) ASCE 37-02: Design loads on structures during construction. ASCE, Reston, VA, USA.

ASCE (2010) ASCE/SEI 7-10: Minimum design loads for buildings and other structures. ASCE, Reston, VA, USA.

BSI (2004) BS EN 1998: Eurocode 8: Design of structures for earthquake resistance. BSI, London, UK.

Bolton MD, Lam SY and Osman AS (2008) Supporting excavations in clay - from analysis to decision making. Proceedings of the 6th International Symposium on Geotechnical Aspects of Underground Construction in Soft Ground, Shanghai, vol. 1, pp. 12-25.

Bray JD, Travasarou T and Zupon J (2010) Seismic displacement design of earth retaining structures. In Proceedings of the $3 \mathrm{rd}$ Earth Retention Conference, ER2010, Seattle (Finno RJ, Hashash YMA, Arduino P and Bellevue WA (eds)). ASCE, Reston, VA, USA, pp. 638-655.

CTBUH (Council on Tall Buildings and Urban Habitat) (2014) http://www.ctbuh.org/ (accessed 18/07/2014).

Callisto L and Soccodato FM (2010) Performance-based design of embedded retaining walls subjected to seismic loading. Proceedings of Workshop on Eurocode 8: Perspectives from an Italian Standpoint, Naples, Italy, pp. 1-10.

Ciria (2001) Building Response to Tunnelling: Case Studies from Construction of the Jubilee Line Extension, London (Burland JB, Standing JR and Jardine FM (eds)). Thomas Telford, London, UK.

Darandeli MB (2001) Development of a New Family of Normalized Modulus Reduction and Material Damping Curves. PhD thesis, University of Texas, Austin, USA.

Davis RV and Henkel DJ (1982) Geotechnical problems associated with the construction of Chater Station, Hong Kong. The Arup Journal 17(1): 4-10.

FEMA (Federal Emergency Management Agency) (2009) NEHRP Recommended Seismic Provisions for New Buildings and Other Structures. FEMA, Washington, DC, USA, FEMA P-750 Report.

Finno RJ, Hashash YMA, Arduino P and Bellevue WA (eds) (2010) Proceedings of the 3rd Earth Retention Conference. ASCE, Reston, VA, USA.

Free MW, Pappin JW, Sze JWC and McGowan MJ (2001) Seismic design methodology for buried structures. Proceedings of the 14th Southeast Asian Geotechnical Conference, Hong Kong, pp. 509-514.

Hashash YMA, Karina K, Demetrious K and O'Riordan N (2010) Seismic design considerations for underground box structures. Proceedings of the ASCE Earth Retention Conference, ER2010, Seattle (Finno RJ, Hashash YMA, Arduino P and Bellevue WA (eds)). ASCE, Reston, VA, USA, pp. 620-637.

Idriss IM and Sun JI (1992) SHAKE91: A Computer Program for Conducting Equivalent Linear Seismic Response Analyses of Horizontally Layered Soil Deposits. Department of Civil and Environmental Engineering, University of California, Davis, CA, USA.

Kaul K (2010) Cut and Cover Metro Structures: Geo-Structural Design: An Integrated Approach. Spon, London, UK.

Kwok OA, Stewart JP, Hashash MA et al. (2006) Practical implementation of analysis routines for nonlinear seismic ground response analysis. Proceedings of the 8th National Conference on Earthquake Engineering, San Francisco. Earthquake Engineering Research Institute, Oakland, CA, USA, Paper S46.

Matthewson MB, Wood JH and Berrill JB (1980) Seismic design of bridges - earth retaining structures. Bulletin of the New Zealand Society of Earthquake Engineering 13(3): 280-293.

NIST (2012) Soil-structure Interaction for Building Structures. NEHRP Consultants Joint Venture under Project ATC-83, National Institute of Science and Technology, Washington DC, USA, Report NIST GCR 12-917-21.

PEER TBI (Pacific Earthquake Engineering Research Center: Tall Buildings Initiative) (2014) http://peer.berkeley.edu/tbi/ (accessed 18/07/2014).

Seed HB and Idriss IM (1970) Soil Moduli and Damping Factors for Dynamic Response Analyses. Earthquake Engineering 
Research Center, University of California, Berkeley, CA, USA, Report No. EERC 70-10.

Seed HB and Whitman RV (1970) Design of earth retaining structures for dynamic loads. In Proceedings of ASCE Specialty Conference, Lateral Stresses in the Ground and Design of Earth-Retaining Structures, Cornell, pp. 103147.

Sitar N, Mikola RG and Candia G (2012) Seismically induced lateral earth pressures on retaining structures and basement walls. In Proceedings of GeoCongress 2012: Geotechnical Engineering State of the Art and Practice (Rollins K and Zekkos D (eds)). ASCE, Reston, VA, USA, Geotechnical Special Publication 226.

Stewart JP, Seed RB and Fenves GL (1998) Empirical Evaluation of Inertial Soil-Structure Interaction Effects. Pacific Earthquake Engineering Research Center, University of California, Berkeley, CA, USA, Report PEER-98/07.

Stewart JP and Tileylioglu S (2007) Input Ground Motions for Tall Buildings with Subterranean Levels, Task 8 Final Report
- Tall Buildings Initiative. Pacific Earthquake Engineering Research Center (PEER). University of California, Berkeley, CA, USA.

Trombetta NW, Hutchinson TC, Mason HB et al. (2012)

Centrifuge modeling of structure-soil-structure interaction: seismic performance of inelastic building models. Proceedings of the 15th World Conference on Earthquake Engineering, Lisbon. International Association for Earthquake Engineering, Tokyo, Japan.

Ukritchon B, Whittle AJ and Sloan SW (2003) Undrained stability of braced excavations in clay. Journal of Geotechnical and Geoenvironmental Engineering, ASCE 129(8): 738-755.

Wood JH (1973) Earthquake Induced Soil Pressures on Structures. PhD thesis, California Institute of Technology, Pasadena, CA, USA.

Yahyai M, Mirtaheri M, Mahoutian M, Daryan AS and Assareh MA (2008) Soil-structure interaction between two adjacent buildings under earthquake load. American Journal of Engineering and Applied Sciences 1(2): 121-125.

\section{WHAT DO YOU THINK?}

To discuss this paper, please email up to 500 words to the editor at journals@ice.org.uk. Your contribution will be forwarded to the author(s) for a reply and, if considered appropriate by the editorial panel, will be published as a discussion in a future issue of the journal.

Proceedings journals rely entirely on contributions sent in by civil engineering professionals, academics and students. Papers should be 2000-5000 words long (briefing papers should be 1000-2000 words long), with adequate illustrations and references. You can submit your paper online via www.icevirtuallibrary.com/content/journals, where you will also find detailed author guidelines. 